\title{
IDENTIDAD Y PICARDÍA MEXICANA
}

\author{
IDENTITY AND MEXICAN SLYNESS
}

\section{GABRIELA OROZCO LÓPEZ1}

RESUMEN: En este trabajo se analiza el derecho a la identidad con base en el uso popular mexicano en comparación con la semántica de la palabra identidad, destacando la imprecisión que brincó del ámbito cultural, al jurídico. En México, el derecho a la identidad se aplica de manera muy diferente a aquellos países precursores de su doctrina. Esta reconstrucción no debe representar un obstáculo para la protección de los derechos de la persona; sin embargo, puesto que la palabra identidad tiene una naturaleza polisémica, aunado al gusto del mexicano por las frases con doble o múltiple sentido, resulta pertinente tener claro cuáles son los elementos y la finalidad del derecho a la identidad. Así, revisaremos la legislación, las tesis y las jurisprudencias mexicanas relativas al derecho a la identidad personal y grupal, para observar la proximidad existente entre la finalidad y la aplicación del derecho, apreciando si en la práctica se consigue la protección de este último.

Palabras Clave: Uso popular de la palabra identidad. El derecho a la identidad en México. Identidad personal. Identidad grupal. Derechos fundamentales.

ABSTRACT: This paper analyzes the right to identity based on popular Mexican usage in comparison with the semantics of the word identity, highlighting the vagueness that leapt from the cultural, to the legal. In Mexico, the right to identity applies very differently to those countries that are the precursors of its doctrine. This reconstruction should not represent an obstacle to the protection of the rights of the person; However, since the word identity has a polysemic nature, combined with the Mexican's

\footnotetext{
${ }^{1}$ Licenciada en Derecho por la Facultad de Derecho de la Universidad Autónoma de Chihuahua; Maestra en Derecho por la Universidad Nacional Autónoma de México. Actualmente, cursa el Doctorado en Derecho, cuyo campo de investigación son los derechos humanos, impartido por el Instituto de Investigaciones Jurídicas de la Universidad Nacional Autónoma de México. <gorozco27@hotmail.com>
} 
taste for phrases with double or multiple meanings, it is pertinent to be clear about the elements and the purpose of the right to identity. Thus, we will review the Mexican legislation, thesis and jurisprudence regarding the right to personal and group identity, in order to look at the existing proximity between the application and its purpose, assessing whether this right is protected in practice.

KEYWORDS: Mexican popular use of the word identity. The right to identity in Mexico. Personal identity. Group identity. Fundamental rights.

SUMARIO: I. Introducción, II La Identidad y su popularidad en México, III. Acepciones de la palabra identidad, IV. La identidad y su relación con los cuestionamientos ¿Quién soy yo? ¿Quiénes somos? ¿Quién eres?, V. El derecho a la identidad, VI. La identidad personal, un derecho fundamental en México, VII. Identidad grupal, VIII. Conclusiones, IX. Fuentes.

\section{I N T RO D U C C I Ó N}

n el trabajo Identidad y picardía mexicana se analiza el derecho a la
identidad con base en i) el uso popular mexicano de la palabra
identidad y ii) la semántica de la palabra identidad, destacando las impresiones que brincaron del ámbito cultural, al derecho mexicano, en el ámbito legislativo y judicial, aspectos que se analizarán en la sección II.

En México, el derecho a la identidad se aplica de manera muy diferente a aquellos países precursores en doctrina y aplicación del mismo, por ejemplo Italia y Argentina. Esta situación no debe representar un obstáculo para la protección de la persona; sin embargo, puesto que la palabra identidad tiene una naturaleza polisémica, aunado con el gusto del mexicano por la expresión imprecisa, el juego de palabras y las frases con doble sentido, resulta pertinente, no perder de vista cuáles son los elementos y la finalidad del derecho a la identidad, aspectos que abordaremos en la sección III del presente trabajo. 
En la sección IV se revisan la legislación, las tesis y las jurisprudencias mexicanas relativas al derecho a la identidad personal, ello con el fin de observar la proximidad existente entre la finalidad del derecho y su aplicación. En cuanto a la sección V, abordamos la identidad grupal como derecho fundamental, concretamente la identidad cultural y la nacional.

Por último para las conclusiones de nuestro trabajo, sección VI, nos pronunciaremos respecto al siguiente cuestionamiento ${ }_{\mathrm{C}}$ En México, se protege, promueve, respeta y garantiza el derecho fundamental a la identidad? ¿Cómo mejorar la protección de este derecho fundamental?

\section{LA IDENTIDAD Y SU POPULARIDAD EN MÉXICO}

El titulo de este ensayo nos traslada a una charla de sobre mesa en la cocina o a una carne asada con los amigos y la familia; en Chihuahua, cuando se aproxima el fin de semana, niños y adultos comienzan a preguntar ¿Sé hace o no se hace? Y unos a otros se miran y hacen la misma pregunta. - ¿Se hace o no se hace? - ¿Qué cosa hija? - Ay mamá, si todos lo saben, - Pero yo no. ¿Qué dices? - ¿Sé hace o no se hace? ¿sé hace o no se hace? Pues, ¿sí se hace la carnita asada? ¿aquí en la casa? Así, con base en un juego de palabras, se organiza la reunión dominical.

Sin duda, los mexicanos encontramos, en diferente medida, cierto gusto por el lenguaje impreciso, es decir, hay una inclinación por dejar abierto el paréntesis, nos deleita pensar en el: “y algo más...”, atrae el doble o múltiple sentido de la palabra. De hecho, es muy popular y demandado el libro titulado "Picardía Mexicana" (1960), del autor Armando Jiménez Farias. En este libro se recopilaron chistes, frases, adivinanzas, pintas y otras expresiones de la cultura popular de la Ciudad de México, cuyo sentido, bajo una rigurosa sintaxis, es sumamente confuso; sin em- 
bargo, esas palabras leídas con los ojos del mexicano tienen alguna representación: una grosería, un albur, categorías e innumerables anécdotas.

Con estos rasgos de la cultura mexicana, se explica la gran oportunidad y proliferación del uso de la palabra identidad.

En todas partes, en los bancos, instituciones educativas, revistas, noticieros, cuentos de super héroes, sentencias y leyes, de muy diferentes maneras escuchamos y leemos discursos que mencionan la identidad; así, se habla de la comprobación de la identidad, identidad cultural, identidad universitaria, identidad de género, doble identidad, identidad secreta, incluso, el día 14 de mayo de 2019, escuché al Subsecretario de Derechos Humanos, Población y Migración de la Secretaría de Gobernación, en la conferencia matutina del presidente de la República, ${ }^{2}$ hablar del derecho a la identidad que tienen los cadáveres para ser identificados; la misma Constitución en su artículo 4, octavo párrafo estipula que toda persona tiene derecho a la identidad y a ser registrado de manera inmediata a su nacimiento. A su vez, la Ley General de los Derechos de Niñas, Niños y Adolescentes, en su artículo tercero intitulado Del Derecho a la Identidad, postula en el artículo 19, las niñas, niños y adolescentes, desde su nacimiento, tienen derecho a: i) Tener nombre y apellidos, así como a ser inscritos en el Registro; ii) Contar con nacionalidad; iii) Conocer su filiación y su origen, siempre que ello sea acorde con el interés superior de la niñez.

Los múltiples sentidos en los que se utiliza la palabra identidad, nos lleva a preguntarnos ¿Qué es la identidad? ¿La identidad será una palabra elástica que sirve para enunciar múltiples ideas y derechos? ¿Por qué en México, la identidad es un derecho fundamental? ¿Qué aspectos

\footnotetext{
${ }^{2}$ Encinas Rodríguez, Alejando, Subsecretario de la Secretaría de Gobernación, Conferencia del Presidente de la República de 14 de mayo de 2019.
} 
de las personas protege el derecho fundamental a la identidad? Estos son los cuestionamiento que abordaremos en el desarrollo del presente trabajo.

\section{ACEPCIONES DE LA PALABRA IDENTIDAD}

La palabra identidad es polisémica y sus significados, no sólo son diversos sino además, pueden ser antónimos; así encontramos, se emplea la palabra identidad tanto para hablar de rasgos comunes o iguales, como para hablar de rasgos diferentes.

Etimológicamente la palabra identidad viene del latín identitas y este de idem cuyo significado es "lo mismo". Por su parte la Real Academia Española señala, la identidad es: 1. Cualidad de idéntico. 2. Conjunto de rasgos propios de un individuo o de una colectividad que los caracterizan frente a los demás. 3. Conciencia que una persona tiene de ser ella misma y distinta a los demás. Entre otras acepciones. ${ }^{3}$

De estas acepciones derivan la multiplicidad de usos que puede tener la palabra identidad; así la utilizamos para destacar rasgos de igualdad como los casos de la identidad universitaria, la identidad cultural, la identidad de género; por el contrario, la empleamos también para definir características individuales y exclusivas; por ejemplo, la comprobación de la identidad, identidad secreta, la doble identidad, el derecho de tener un acta de nacimiento.

Por sí misma es compleja la palabra identidad, cuyas acepciones son antónimos; en el ámbito jurídico, lograr precisar el derecho a la identidad es más complicado, ya que se agrega un tercer elemento para su configuración: la conciencia, es decir, la identidad implica que existe la voluntad de ser uno mismo,

\footnotetext{
${ }^{3}$ Diccionario de la Real Academia Española, 20 de mayo de 2019, https://dle.rae. es/?id=KtmKMfe
} 
igual a algunos y, al mismo tiempo, diferente a todos. La jurista Uría Acevedo, al referirse a la identidad personal, considera que: "Un aspecto central de la identidad es el desarrollo de la conciencia de que uno es uno mismo y siempre el mismo a través de los múltiples cambios que se viven a lo largo de la vida. Es necesario que aquí se combinen estabilidad y dinamismo.” 4

En este contexto, me resulta oportuno señalar que los cadáveres, si bien tienen derecho a ser identificados, con la muerte, al terminar la conciencia, desaparece cualquier vestigio de identidad. Consideramos que el único derecho de la persona que permanece, espacial y temporalmente hablando, es el nombre, el cual es un derecho fundamental diferente a la identidad. La explicación se amplía en la secciónn III, relativa al concepto, elementos y finalidad de la identidad.

En México, la popularidad de la palabra identidad se trasladó al ámbito jurídico, esto aumentó la impresión de la aplicación del derecho. La regulación y aplicación del derecho a la identidad le ha quitado cobijo a otros derechos fundamentales como el nombre, la nacionalidad, los alimentos, e incluso, la misma identidad personal ha quedado desprotegida en parte, según lo abordaremos en el desarrollo del presente trabajo.

La presencia de la conciencia en el fenómeno de la identidad, significa que la persona tiene el derecho a preguntarse y a investigar, lo siguiente: ¿quién soy yo? ¿quiénes somos nosotros?, ¿quién eres? Estas preguntas nos aproximan al significado de la identidad.

\footnotetext{
${ }^{4}$ Uría Acevedo, María de las Mercedes Ales, El derecho a la identidad en la filiación, Valencia, Tirant lo Blanch, 2012, p. 408.
} 


\section{LA IDENTIDAD Y SU RELACIÓN CON LOS CUES- TIONAMIENTOS ¿QUIÉN SOY YO? ¿QUIÉNES SOMOS? ¿QUIÉN ERES?}

La investigadora en el campo del derecho familiar, Blanca Gómez Bengoechea señala que: "La identidad, desde una perspectiva psicológica, es una cuestión difícil de définir teóricamente y con múltiples dimensiones, significados y funciones. Tiene que ver con cómo la persona responde a la triple pregunta de quién soy yo, de dónde vengo y a dónde voy" Este texto se refiere a la identidad personal y sus relaciones con la figura de la adopción y la filiación, de ahí que se omita la pregunta relativa a la identidad grupal ¿quiénes somos?

Otra diferencia con la triple pregunta de la jurista española, nosotros planteamos además que el derecho a la identidad se relaciona con los cuestionamientos quién eres y quiénes son ustedes, ello en razón de que nosotros pensamos, este derecho se conforma con dos tiempos, i) el proceso interno que lleva conscientemente el individuo respecto a sus propia características, y ii) la percepción que tienen los demás de esas características. En este sentido, el jurista peruano Carlos Fernández Sessarego advierte que:

(...) el interés que aparece como susceptible de tutela, correspondiente a la identidad, no es de fácil percepción. Ello no sólo por su profundidad, sino también por su ambigüedad consubstancial, en tanto que sobre la identidad pueden confrontarse dos versiones no necesariamente coincidentes: la que cada cual tiene de su "verdad personal” y la visión que poseen los demás de dicha personalidad. ${ }^{6}$

\footnotetext{
${ }^{5}$ Gómez Bengoechea, Blanca, Derecho a la Identidady filiación: búsqueda de onígenes en adopción internacional y en otros supuestos de filiación transfronteriza, Madrid, Dykinson, 2007, p. 28

${ }^{6}$ Fernández Sessarego, Carlos, "Derecho a la identidad Personal”, Comparazione e Diritto Ciwile, 1992, p. 29, http://werere.comparazionedinittociwile.it/prova/files/sessarego_derecho.pdf
} 
Nosotros estamos de acuerdo con la reflexión del jurista Fernández Sessarego; la identidad comprende dos tiempos o dos versiones e implica la relación entre las preguntas ¿quién soy? Y como los demás captan ¿quién eres?

Por último, distinto a la Jurista Gómez Bengoechea, proponemos se realice la pregunta ¿quién soy?, de manera independiente con relación a las interrogantes ¿de dónde vengo?, y ¿a dónde voy?, pues creemos que estas últimas pueden condicionar a la primera e impedir el libre desarrollo de la identidad.

Para que la identidad tenga el carácter de derecho subjetivo, supone una apreciación con elementos dinámicos y flexibles, de lo contrario, representaría un fundamento para la estática social. La vinculación entre el quién soy y de dónde vengo y a dónde voy, me recuerda la frase "Origen es destino", citada en el artículo "Pobre naces, pobre te quedas" de Mathieu Tourliere. ${ }^{7}$ Por ello preferimos destacar los elementos dinámicos del derecho a la identidad, los cuales se estudiarán en las sección III de este trabajo.

Realizadas estas acotaciones, abordaremos las preguntas planteadas. Primero ¿quién soy yo? Esta es una pregunta muy seria, casi enigmática; Hamlet lo expresó de este modo: “Ser o no ser, es la cuestión! (...) Ser o no ser, todo el problema es ése". ${ }^{8}$ En la Biografía de Tadeo Isidoro Cruz (1829-1874), Jorge Luis Borges hizo un poema de esa reflexión: "Cualquier destino, por largo y complicado que sea, consta en realidad de un solo momento: el momento en que el hombre sabe para siempre quién

7 Tourliere, Mathieu, "Pobre naces, pobre te quedas", Revista Proceso, 18 de mayo de 2019, https://www.proceso.com.mx/584668/pobre-naces-pobre-te-quedas: La frase describe la situación de la movilidad social en el país: ocho de cada 10 mexicanos que nacen en las familias más pobres nunca superan esta condición; en el extremo opuesto, siete de cada 10 que nacen en el $20 \%$ de hogares con mayores recursos nunca descienden al escalón inferior.

${ }^{8}$ Shakespeare, William, La tragedia de Hamlet, principe de Dinamarca, Londres, 1605. 
es”. ${ }^{9}$ Más cerca, en términos espaciales y temporales, el 10 de Mayo de 2019, escuché en la voz de la escritora Sabina Berman, algunas reflexiones sobre el "yo", la entrevista fue realizada por Julio Astillero en Radio Centro:

Sabina: (...) como a los 15 años, con las hormonas, me viene un estallido del lenguaje y leía mucho, me encantaba leer, pero entonces, no sabía yo quién era y eso me angustiaba y tenía yo que definir que iba a estudiar, (...) Julio: Tardaste en encontrar quien eras... y ahora ¿quién eres...? Sabina: Esa es muy buena pregunta y muy aguda - se ríe - Continúa Sabina: Soy una presencia, no me tengo tan claramente definida eeeh.. por eso escribí ejercicios fantásticos del yo, uno de mis gurús es Fernando Pessoa que se dijo a sí mismo, si el yo es un cuento que el yo se cuenta sobre que es el yo, por qué no me cuento que soy tres yo, o diez, o treinta y tres y así fue treinta y tres yos. Mi solución fue distinta, pero me dio mucha tranquilidad entender que el yo... hay una presencia física que somos y después está todo el rollo que contenemos (...) ${ }^{10}$

Ante todas estas complejas reflexiones de ¿Quién soy yo? lo primero que me viene a la mente ¿Cómo y por qué el derecho pretende regular la identidad? Recordemos, una característica de las normas jurídicas es la exterioridad, en tanto, la identidad es intima, interna y profunda. La doctrina aclaró esta cuestión, al distinguir como parte del derecho a la identidad, la percepción que tienen los demás de ese proceso interno de la persona; por ello, consideramos, el derecho a la identidad comprende dos tiempos, el primero es interno, en el cual uno a sí mismo se plantea ¿Quién soy yo?, o, ¿Quiénes somos nosotros? y el segundo o externo cuando con base en percepciones se define ¿Quién eres?, ¿Quiénes son ustedes?

9 Borges, Jorge Luis, "Biografía de Tadeo Isidoro Cruz (1829-1874)", El Aleph, Buenos Aires, 1949.

${ }^{10}$ Berman Sabina, Entrevista de 10 de mayo de 2019, con Julio Astillero en Radio Centro. 
No sólo la doctrina justificó el derecho a la identidad. En Argentina, la vulneración a este derecho fue atroz, la dictadura militar que dio el golpe de estado, en el año de 1976, se caracterizó por la constante violación a los derechos humanos, por la desaparición y muerte de miles de personas y por la apropiación sistemática de recién nacidos, además de otros crímenes de lesa humanidad.

En Argentina el derecho a la identidad tuvo el rostro de cientos de niños y niñas recién nacidos secuestrados por el Estado, cuyos nombres fueron borrados. Ramón Camps, jefe de la policía de la provincia de Buenos Aires, decía: "Personalmente yo no eliminé a ningún chico, lo que hice fue dar algunos a organizaciones benéficas para que les encontraran nuevos padres. Los subversivos educan a sus hijos en la subversión. Por ello esto debía detenerse". ${ }^{11}$ Esta última frase "los subversivos educan a sus hijos en la subversión”, tiene una fuerte carga de aquello que comprende la identidad. Fue entonces, cuando las abuelas de los recién nacidos, desconsoladas y valerosas, formaron la asociación Abuelas de Plaza de Mayo, para apoyarse en la búsqueda de los suyos, cuya bandera constitutiva, no definida todavía, fue precisamente el derecho a la identidad de sus nietos arrebatados.

La crueldad e invasión del Poder Estatal, en esferas tan intimas de la persona como la relativa a la crianza de los hijos, es lo que llevo a la América Latina a erigir como derecho fundamental el derecho a la identidad.

Ahora bien, ubicados los dos tiempos del derecho a la identidad, el interno y el externo; regresemos al primer momento, el interno. Supongamos, qué tal que "yo" no encuentro ni tengo problema con el ¡Ser o no ser! Simplemente soy y hasta que me muera dejaré de ser; y, aunque

\footnotetext{
${ }^{11}$ Mayo 2019, https://es.wikipedia.org/wiki/Abuelas_de_Plaza_de_Mayo
} 
me parece un poema cada palabra del escritor Jorge Luis Borges, quiero pensar que el hoy por hoy es mi destino; por otra parte, tampoco me angustia como a la escritora Berman, la pregunta, quién soy, por el contrario, lo que me robaría la paz es la idea de concebir más de un yo, dos, tres, diez o treinta y tres. Definitivamente no, yo no puedo. Me parece una fantasía de miedo. Además, los cuento del “yo” me restarían demasiado tiempo y pensamientos. En absoluto, no me gustan.

Entonces, cómo respondo a ¿quién soy yo? Ami lo que me place es asumir que soy la que veo en el espejo y lo que dice mi acta de nacimiento. Sin más, ésta soy yo y ya. ¿Y por qué no? Esta certidumbre es mi derecho a la identidad.

Argentina vivió y conoce el desasosiego y sufrimiento que implica la vulneración al derecho a la identidad, por ello también ha profundizado sobre el derecho a no saber como parte del derecho a la identidad. La certidumbre puede incidir o regir el proceso interno que conforma la identidad. Al respecto el jurista argentino Luis Daniel Crovi afirma: "La Corte Suprema ha elaborado una doctrina que protege tanto el derecho de conocer los orígenes como 'el derecho a no saber". ${ }^{12}$

El derecho mexicano, considero, debería excursionar sobre el derecho a no saber, a fin de proteger de una manera más precisa y amplia el derecho a la identidad de las personas, situación que analizaremos al revisar las tesis jurisprudenciales emitidas.

Segundo, la pregunta ¿quiénes somos?, la relacionamos con la identidad grupal; el jurista Crovi dice: "La identidad de un grupo no debe ser entendida como la suma de las identidades de las personas que lo componen, pues se refiere a una calidad compartida o lazo de cohesión,

\footnotetext{
${ }^{12}$ Crovi, Luis Daniel, "El Derecho a la Identidad y sus Alcances”, Derecho de Familia y de las Personas, Argentina, año VI, número 3, abril 2014, pp. 219 y 220.
} 
que los integra dentro del conjunto." 13

Consideramos que el lazo de cohesión grupal se refiere a un proceso interno por el que el individuo identifica conscientemente rasgos propios que son comunes en otras personas, lo que da la sensación de pertenencia recíproca, es decir, a la persona le pertenece el grupo y, a su vez, al grupo le pertenece la persona; en cuanto a los grupos, estos pueden ser muy variados, por ejemplo, la nación, pueblos indígenas, la familia, la universidad, un partido político, una asociación, hasta una banda delictiva.

Tercero, en cuanto a las preguntas ¿quién eres? ¿quiénes son?, reiteramos, estas se relacionan con la identidad en el segundo tiempo, en la exteriorización y la percepción de los rasgos internos, a lo que el jurista Carlos Fernández Sessarego llama la visión que poseen los demás de la personalidad o el grupo.

Si bien las preguntas internas ¿quién soy? ¿Quiénes somos? Se atienden de una manera muy seria, casi enigmática, en México, definir a los demás aparentemente es muy fácil. Como si fueran flechas se asignan identidades: los chairos, fifis, pirrruris, ninis, pikis, cuquis, nacos, turistas indeseados, la perrada, etc., por mencionar algunas de las categorías escuchadas recientemente en voces públicas; lo curioso es que, la percepción o exteriorización de la identidad, lejos de ofender, nos causa mofa y hasta hay quienes optan por asumir las percepciones, muy a la mexicana, en diversos sentidos.

Ahora bien, creo que para una adecuada promoción, respeto, protección y garantía del derecho a la identidad, se deben equilibrar los tiempos en los que la identidad personal se conforma, primero el interno y segundo el externo. Al primero, pudiéramos restarle profundidad, proponer alternativas como el derecho a no saber de dónde venimos, si ello nos afecta y condiciona a dónde vamos; otra buena opción, llamarle a los

\footnotetext{
${ }^{13}$ Ibidem, p. 221.
} 
derechos por su nombre, con precisión de acuerdo a su finalidad, por ejemplo, derecho a la identidad, derecho al nombre, derecho a alimentos, nacionalidad, registro de nacimiento. En tanto, al segundo tiempo, sería sano restarle trivialidad, podríamos trasladar la seriedad que sobra de las preguntas, quién soy, quiénes somos, por ejemplo, mi familia y yo, a los cuestionamientos, quién eres, quiénes son ustedes. Los mexicanos, según algunas encuestas, somos personas alegres pero no por ello debemos contarnos como si fuéramos chistes de picardía mexicana: chairos, fifis, pirrruris, ninis, pikis, turismo no deseado, la perrada...

En cuanto a este segundo momento, la exteriorización de la personalidad, el Jurista Fernández Sessarego señala que la visión que tienen los demás, no puede delinear una determinada personalidad, en otras palabras, es necesario también el primer momento la interiorización o la formulación de la pregunta quién soy; sin embargo, la exteriorización viene a confirmar la verdadera personalidad, así cita al filósofo Emanuel Mounier, en El Personalismo:

No obstante su capacidad de desvirtuar la identidad personal, la mirada no fija ni petrifica al ser humano. La "mirada", aunque no refleja a la persona tal cual es, constituye una expresión de la comunicación interpersonal. Ello lleva a decir a Mounier que a pesar que la "mirada" es hostil y nos trastorna, no obstante que "atropella mi seguridad, mis hábitos, mi sueño egocéntrico”, se constituye en "el más seguro revelador de mí mismo.” 14

Este texto corrobora la necesidad de equilibrar los momentos en los que se conforma la identidad personal, la interiorización y la exteriorización, ya que finalmente esta última viene a a complementar la primera, para revelar la verdadera personalidad.

\footnotetext{
${ }^{14}$ Fernández Sessarego, Carlos, op. cit., p. 7
} 


\section{EL DERECHO A LA IDENTIDAD \\ 1. CONCEPTO}

Por caminos diferentes se erigió el derecho a la identidad; mientras que en Italia la doctrina y los Tribunales definían el derecho a la identidad, analizando casos de robo de identidad, colisión de derechos como el interés de exteriorización de la personalidad contra la libertad de expresión y otros casos recursos del derecho a la identidad; en Argentina durante la última dictadura, 1976, se violaba sistemáticamente el derecho a la identidad de las familias y recién nacidos secuestrados por el Estado. Así, en ambos contextos trascendió el estudio de las preguntas ¿quién soy? ¿quién eres?, sin embargo, su análisis jurídico se focalizó en elementos diferentes del derecho a la identidad.

En Italia la doctrina enfatizó los elementos dinámicos del derecho a la identidad, por ejemplo, la conciencia, el sentido de pertenencia, la imagen y en general las características y manifestaciones morales, sociales, políticas, intelectuales, etc. En tanto, en Argentina, la protección del derecho a la identidad destacó los elementos estáticos, por ejemplo la genética, la fecha de nacimiento, el lugar de nacimiento, el nombre y la filiación; así, ambos países atendieron sus problemáticas específicas. Italia, resuelve casos de robo de identidad, vulneración a los elementos dinámicos del derecho a la identidad y otros: por su parte, en Argentina, la asociación de Abuelas Plaza de Mayo y afectados han ido encontrando a los entonces recién nacidos arrebatados de sus familias.

México adoptó la postura de Argentina, desarrolló el derecho a la identidad con base en sus elementos estáticos, por ejemplo el nombre, apellidos, registro civil, filiación, nacionalidad, verdad biológica y pertenencia cultural, según se establece en la Ley General de los Derechos 
de Niñas, Niños y Adolescentes. Es más, México superó la tendencia de Argentina, ya que elevó los elementos estáticos del derecho a la identidad, a derecho fundamental; en cambio, en Argentina el derecho a la identidad personal no tiene el carácter de fundamental.

Ahora bien, los conceptos del derecho a la identidad pueden ser de tres tipos, a) los que consideran los elementos dinámicos, b) los que consideran los elementos estáticos, y c) los que comprenden tanto los elementos dinámicos, como los estáticos de la identidad. Agregamos d) nuestra postura.

a) En cuanto a los conceptos que consideran los elementos dinámicos de la identidad, encontramos la definición de la doctrina italiana, expresada mediante ejecutoria de 22 de junio de 1985, emitida por el prestigioso Tribunal de Casación: ${ }^{15}$

Para los magistrados supremos los signos distintivos, como el nombre y el seudónimo, identifican al sujeto en el "plano de la existencia material y de la condición civil y legal”, mientras que la identidad es "una fórmula sintética que distingue al sujeto desde el punto de vista global en sus específicas características y manifestaciones”. Es decir, de sus expresiones morales, sociales, políticas, intelectuales, profesionales, todo lo que hace patente "la concreta y efectiva personalidad individual del sujeto". ${ }^{16}$

También, hay un sector de la doctrina argentina que destaca los elementos dinámicos de la identidad, sosteniendo que "este derecho personalísimo es el reconocimiento de la formación de la personalidad moral, no con relación al concepto abstracto de personalidad jurídica, por ser ente susceptible de adquirir derechos y contraer obligaciones, sino de la

\footnotetext{
${ }^{15}$ Corte de Casación Italiana, 22 de junio de 1985, caso Veronesi.

${ }^{16}$ Fernández Sessarego, Carlos, op. cit., p. 19
} 
personalidad anímica, psicológica y social de hombre”. ${ }^{17}$

La ventaja de esta corriente, es que hace una clara distinción entre el derecho a la identidad y otros derechos como el del nombre, la nacionalidad, la filiación, la intimidad, lo cual nos permite una protección más amplia a los derechos humanos, incluyendo el mismo derecho a la identidad.

b) Respecto al concepto con elementos estáticos, el derecho a la identidad en México es el ejemplo inmediato. La investigadora mexicana Karla Cantoral Domínguez señala que:

En la doctrina tradicional se consideraba el derecho a la identidad asociado al nombre de una persona que se emite a partir de la expedición de su acta de nacimiento por parte del Registro Civil, lo que le permite relacionarse dentro del grupo social en el que convive, sin embargo a partir de la constitucionalización del derecho civil, encontramos que el derecho a la identidad tiene que ver con el derecho de toda persona a conocer sus orígenes así como a tener información sobre su verdad biológica y preservarla. ${ }^{18}$

Esta concepción del derecho a la identidad se fundamenta en el artículo 4o, octavo párrafo de la Constitución Política de los Estado Unidos Mexicanos, en correlación con el artículo 19 de la Ley General de los Derechos de Niñas, Niños y Adolescentes.

En México, hay un criterio generalizado que considera un solo derecho, la identidad y el nombre, o bien, si se aprecia alguna distinción

${ }^{17}$ Cifuentes, Santos, "Protección jurídica de la vida privada y de la identidad personal”, Anales de la Academia Nacional de Derecho y Ciencia Sociales de Buenos Aires, año XLVI, número 39, 2001, p. 25

${ }^{18}$ Cantoral Domínguez, Karla, "Construcción jurisprudencial del derecho a la identidad”, Nexo Furídico, Focus Regit Actum, México, año VI, número 23, octubre - diciembre 2014, p. 53. 
consiste en que la primera se presume género y y el segundo, especie. Así, por ejemplo el artículo 13 de la Ley General de los derecho de niñas, niños y adolescentes, emitida el 4 de diciembre de 2014, establece que son derechos de los menores mencionado el derecho a la identidad, en tanto, el artículo 19 del mismo ordenamiento refiere que la identidad, comprende, el nombre, los apellidos, inscripción en el registro civil, nacionalidad, filiación, conocimiento de sus orígenes, pertenencia cultural y relaciones familiares. Este criterio es equivoco y provoca deficiencias en la protección del derecho a la identidad y el derecho al nombre.

La identidad y el nombre son derechos interdependientes pero diferentes, ya que sus elementos y finalidades son también distintas. La Corte de Casación, en la ejecutoria de 22 de junio de 1985, expresó con precisión esa distinción: (...) entre el derecho a la identidad personal y el derecho al nombre existe tan sólo una cierta correlación. No puede considerarse, por ende, que el derecho a la identidad esté comprendido dentro de los alcances conceptuales del derecho al nombre, que tiene que ver con la identidad estática o “identificación”. ${ }^{19}$

En efecto, cuando queremos conocer e identificar a una persona, lo primero que preguntamos es ¿cómo te llamas? Mi nombre es Fulanita o Manganito Rata Taa. Expresado un nombre, todos los rasgos de identificación de la persona, como la imagen, quehacer, edad, domicilio, etc., se vinculan al primero. En el mismo sentido, el primer dato que el Estado recaba de la persona, es el nombre, el cual se integra por dos elementos: i) nombre (s) propio (s) y ii) patronímico (s). Nunca nadie, ni particulares ni Estado, preguntan ¿cuál es tu identidad? La respuesta refleja sería - ¿Qué? ¿cómo dices? En cuanto al registro de nacimiento, en ningún lugar del acta se asienta el dato "la identidad del recién nacido",

${ }^{19}$ Fernández Sessarego, Carlos, op. cit., p. 19 
ni tampoco se asientan los datos genéticos ni su comparativo molecular con el de los supuestos padres. Esto se explica, porque la identidad no es el nombre, son derechos distintos. Asimismo, la identidad personal representada con las preguntas "quién soy - quién eres", tiene como finalidad la individualización de las personas, no, su identificación.

Ahora bien, el 17 de junio de 2014, los elementos estáticos de la identidad se elevaron a derecho fundamental en México, copiando una característica del derecho a la identidad en Argentina, consistente en destacar el derecho a conocer los orígenes o verdad biológica de la persona. Me parece que esta característica fue una mala copia para México, ya que i) La problemática de México y Argentina es diferente, en Argentina el derecho a la identidad tuvo el rostro de cientos de recién nacidos secuestrados por la dictadura militar de 1976, cuyos familiares sembraron en la población la inquietud siguiente: "si naciste en los años 1976 a 1978, en Argentina en las regiones tales, y sientes que hay algo en tu familia que no explica quién eres, por ejemplo el físico, el afecto, o cuestiones reveladas por la intuición, acude a la Plaza de Mayo.” Así el desasosiego de adolescentes, jóvenes y adultos en torno al cuestionamiento ¿quién soy yo? Permitió el encuentro de numerosas familias argentina, abuelas y nietos. En tanto, en México, el ejercicio del derecho a conocer los orígenes, no es motivado por la interiorización del quién soy yo, sino, en la mayoría de los casos, se utiliza para imputar o deslindar obligaciones alimentarias, con relación a un menor. ii) Mientras que en Argentina el derecho a la identidad se integra por el derecho a saber, pero también el derecho a no saber, los orígenes de la persona. En México, la legislación no establece el derecho a no saber, por su parte, los Tribunales mexicanos comienzan a lidiar con esa problemática de manera no sistematizada, argumentando a favor del interés superior de la niñez, a fin de que la verdad biológica no sea 
un elemento suficiente para determinar la filiación de un menor en litigio. iii) En Argentina la identidad no es un derecho fundamental y en México si; lo que llama nuestra atención es que, si bien en México el derecho a la identidad es protegido por nuestra Constitución, lo cierto es que hay muy poca relación entre este derecho y las preguntas quién soy - quién eres. En nuestra legislación el derecho a la identidad se reduce al registro de nacimiento y, en la regulación secundaria se especifica que la identidad comprende el nombre y su registro, nacionalidad, filiación y el derecho a conocer sus orígenes. Estas disposiciones promueven más otros derechos, como el del nombre y su registro, nacionalidad y derecho de alimentos que el respeto estatal a los cuestionamiento personales quién soy - quién eres, es decir, el derecho a la identidad personal.

c) En cuento a los conceptos del derecho a la identidad con elementos dinámicos y estáticos, el Jurista peruano Carlos Fernández Sessarego es partidario de esta corriente, define la identidad personal como: el conjunto de atributos y características psicosomáticas que permiten individualizar a la persona en sociedad. Identidad personal es todo aquello que hace que cada cual sea "uno mismo" y no "otro". Este plexo de rasgos de la personalidad de "cada cual" se proyecta hacia el mundo exterior y permite a los demás conocer a la persona, a cierta persona, en su "mismidad", en lo que ella es en cuanto ser humano. ${ }^{20}$ Se amplía la explicación con el siguiente texto:

"la identidad personal comprende ambos aspectos: el estático, que tiene que ver con los signos distintivos y con la existencia material y la condición legal o registral del sujeto (nombre, seudónimo, etc.), y la dinámica, que es el conjunto de características y rasgos de índole cultural, política, sicológica, moral de la persona, aunque advertimos que en la actual doctrina, por el afán de diferenciar ambas facetas, se tiende a reservar

${ }^{20}$ Fernández Sessarego, Carlos, op. cit., p. 27 
la noción de identidad personal para designar esta vertiente espiritual y mudable del sujeto. ${ }^{21}$

En sentencias emitidas por la Corte Interamericana de Derechos $\mathrm{Hu}-$ manos se define el derecho a la identidad como "el conjunto de atributos y características que permiten la individualización de la persona en sociedad y, en tal sentido comprende varios otros derechos según el sujeto de derechos de que se trate y las circunstancias del caso.” 22

Si bien, la Corte Interamericana de Derechos Humanos no especifica si los atributos o características de las personas son de índole estático o dinámico, nosotros presumimos que se trata ambos, ya que por un lado habla de individualidad, la cual a diferencia de la identificación, requiere los elementos dinámicos que aporta la conciencia, y por el otro, habla de atributos de la personalidad y de la comprensión de varios derechos (en el derecho a la identidad) según el sujeto de que se trata, lo cual nos hace pensar en los elementos estáticos como el nombre, filiación y nacionalidad.

d) Nuestra postura está más cerca de la doctrina italiana, nos parece conveniente definir la identidad personal mediante los elementos dinámicos que aporta la conciencia. En este sentido, la identidad personal se integra con las característica y rasgos que las personas encontramos en nosotros mismos, algunos de estos rasgos son iguales a los de otros, por ejemplo a los integrantes de la nación, etnia, familia, universidad, religión, partido político, grupo de amigos, etc; y, a su vez, el conjunto de rasgos y características, nos permite asumirnos conscientemente como seres únicos y diferentes a todas las demás personas.

\footnotetext{
${ }^{21}$ Fernández Sessarego, Carlos, op. cit., p. 32

22 Caso Gelman Vs Uruguay, 24 de febrero de 2011, Corte Interamericana de Derechos Humanos.
} 
Además, el proceso de la identidad personal deberá ser guiado por los cuestionamientos, quién soy - quién eres, recordemos a los grandes pensadores Shakespeare, Jorge Luis Borges, Sabina Berman, y las acotaciones realizadas en la sección II, numeral 2, del presente trabajo; por ello, los elementos estáticos de la personalidad como la genética, el nombre, la filiación y lugar de nacimiento, pueden incidir en la definición de la identidad siempre y cuando tengan como finalidad responder a esos cuestionamientos; por ejemplo, así sucedió en Argentina, se introdujeron elementos estático para desentrañar la inquietante pregunta ¿quién eres en verdad si has nacido durante la última dictadura?

Por otra parte, los elementos dinámicos de la identidad nos permiten distinguir entre éste y los otros derechos como el nombre.

En términos antropológicos es característico del hombre primitivo relacionar la identidad personal con el nombre. El antropólogo escocés James George Frazer expone: El salvaje imagina, por lo general, que el eslabón entre un nombre y el sujeto u objeto denominado no es una mera asociación arbitraria e ideológica, sino un verdadero y sustancial vínculo que une a los dos de tal modo que la magia puede actuar sobre una persona tan fácilmente por intermedio de su nombre, como por medio de su pelo, sus uñas o cualquiera otra parte material de su persona. ${ }^{23}$

Para los pueblos primitivos, la palabra que tiene la función de nombre propio alude a una significación propia en su origen, y quienes los asignan, buscan o establecen una relación entre la idea, cosa o animal que la voz significa, y el individuo a quien el nombre está destinado. Es una relación que puede ser adjetiva, de validez o una expresión de esperanzas o de deseos o simplemente una expresión fonéticamente bella. ${ }^{24}$ Refiere

${ }^{23}$ Frazer, James George, La rama dorada: Magia y religión, 3a ed., trad. de Elizabeth Campuzano y Tadeo I. Campuzano, México, Fondo de Cultura Económica, 2011, p. 290

${ }^{24}$ Pliner, Adolfo, El nombre de las personas, 2a ed., Argentina, ASTREA, 199X, p. 3 
el antropólogo Lewis H. Morgan que en una "gens" omaha (aborígenes de la América del Norte) halló nombres de varón com "Ala larga”, “Gavilán que se Cierne en el Aire” “Ave de Ojos Blancos”, y nombre de mujer como "Ave que Canta en la Alborada" o "Huevo de Pájaro" ${ }^{25}$

En la civilización moderna aún encontramos vestigios del vínculo entre la magia y el nombre, los relacionamos i) la multiplicidad de nombres propios se asocia con la intención religiosa y mística de brindar protección al recién nacido. Por ejemplo, nuestro compositor e interprete Agustin Lara: Ángel Agustín María Carlos Fausto Mariano Alfonso del Sagrado Corazón de Jesús Lara y Aguirre del Pino. ii) Quién no conoce el proverbio latino "nomen est omen", el nombre es destino; se cree que nombrar no es una mera imposición fonética sobre los seres y las cosas, sino también se indica al individuo un lugar en el orden del mundo. iii) En México existe el criterio generalizado de que la identidad personal y el nombre, son lo mismo y pueden protegerse con la enunciación del mismo derecho fundamental y las mismas disposiciones legales.

Como hemos visto, la identidad es una palabra polisémica, cuyos significados son antónimos; a su vez el derecho a la identidad es polisémico, por ejemplo, existen los derechos a la identidad personal, a la identidad cultural, a la identidad de género, el derecho de la víctima para proteger su identidad y cada uno de estos protege diferentes aspectos de la persona; por la parte cultural, encontramos el gusto del mexicano por la palabra imprecisa, las frases con doble o múltiple sentido, el juego de palabras, popularmente se conoce como picardía mexicana. Ante todas estas condiciones que favorecen los malos entendidos ${ }_{\mathrm{C}}$ Por qué en México definimos el derecho a la identidad con base en los elementos estáticos de ésta?, los elementos estáticos son otros derechos diferentes,

${ }^{25}$ Morgan, Lewis Henry, La sociedad primitiva, Madrid, Ayuso, 1970, t. I, p. 141 
algunos incluso también fundamentales como el derecho al nombre, la nacionalidad y los alimentos. En este contexto, es apremiante introducir y enfatizar los elementos dinámicos del derecho a la identidad, los cuales pueden reconciliar el derecho a la identidad en México con los cuestionamientos: quién soy yo - quién eres.

\section{ELEMENTOS}

De los concepto analizados se desprende que el derecho a la identidad tiene dos tipos de elementos, los estáticos y los dinámicos.

a) Los elemento estáticos del derecho a la identidad pueden ser el nombre, la genética, la filiación, la nacionalidad, el género, la fecha de nacimiento, el lugar de nacimiento, el matrimonio, según tesis jurisprudencial de la Suprema Corte de Justicia de la Nación, y, en general, todos aquellos que permitan definir quién soy yo - quién eres.

No quiere decir que los elementos estáticos sean inmutables; todo cambia y estos elementos o condiciones también, inclusive, entiendo que la genética y el género pueden ser alterados con las técnicas genéticas, hormonales y quirúrgicas médicas. Por elementos estáticos entendemos aquellos que permanecen en un estado sin cambios periódicos.

b) Los elementos dinámicos de la identidad son aquéllas características y rasgos determinados por la conciencia, los cuales cambian según nuestras vivencias; estos nos ayudan a delimitar internamente quién soy y externamente reflejan quién eres. Estos rasgos se conforman por el comportamiento, quehacer, creencias, grupos de pertenencia, virtudes y vicios, lugares favoritos, historias y experiencias, certidumbres y temores, amores y odios, etc. Los elementos dinámicos cambian continuamente hasta que la persona muere. 
Son los elementos dinámicos los que distinguen el derecho a la identidad personal, del resto de los atributos de la persona y de los derechos que protegen la existencia material y legal del ser humano.

\section{FINALIDAD}

De los conceptos del derecho a la identidad se desprenden las siguientes finalidades:

a) Individualidad - identificación. Por individualidad se entiende los rasgos y características que expresamos y nos hacen diferentes al resto de las personas; en otras palabras, la individualidad muestra que él o ella es precisamente él o ella y no otro u otra, la individualidad significa que somos únicos e irrepetibles. En tanto la identificación es la individualidad con nombre y apellido. La identificación implica la obligación de responder ¿quién eres? ¿Y con qué acreditas tu nombre?

Considero que la finalidad del derecho a la identidad es la individualización; la identificación es una finalidad del derecho al nombre. De hecho cuando el Estado y los particulares quieren identificar a una persona indagan sobre su nombre, después sobre los otros rasgos distintivos de la personalidad.

b) Pertenencia - permanencia, los rasgos en nuestra persona, comunes con otras personas, por ejemplo el lenguaje, las historias, los lugares favoritos, nos dan la sensación de pertenencia, es decir, hay un sentimiento recíproco de que el grupo pertenece a la persona y la persona pertenece al grupo. Esta finalidad de la identidad se evidencia en la identidad grupal y cultural, de manera indirecta en la identidad personal, ya que la primera puede incidir en la segunda. 
En cuanto a la permanencia, esta es una finalidad del derecho al nombre, no de la identidad, por ello es inadecuado hablar del derecho a la identidad de los cadáveres. La identidad no es sinónimo de identificación, lo analizamos previamente sus significados son diferencia e igualdad de rasgos. Asimismo, la concepción de la identidad es posible mediante la conciencia; los elementos dinámicos, la psique y los espirituales, son los que hacen de la persona un ser único, sin embargo, al morir termina también la posibilidad de descifrar ¿quién soy? - ¿quién eres? Así acaba el derecho a la identidad. El único derecho que trasciende temporal y espacialmente hablando es el nombre de la personas, por ende, la permanencia es finalidad del derecho al nombre no de la identidad.

c) Verdad biológica - filiación. Esta finalidad, que a su vez es un elemento estático del derecho a la identidad, tiene sus orígenes en la última dictadura de Argentina, cuando en el año de 1976 y subsiguientes, el Estado robó cientos de recién nacidos para que fueran criados por otras familias en "la decencia versus la subversión". En México se introdujo el derecho fundamental a conocer los orígenes y verdad biológica de la persona, como parte del derecho a la identidad, en el año de 2014.

Consideramos que los aspectos de la verdad biológica, la filiación e inclusive la crianza inciden directamente en la identidad de la persona. Sin embargo, no hay que perder de vista que el derecho a saber o, en su caso, a no saber sus orígenes debe dirigirse siempre a los cuestionamiento quién soy yo - quién eres; de lo contrario, si conocer la verdad biológica tiene como finalidad imputar o deslindar obligaciones alimentarias, el derecho o derechos fundamentales que se buscan proteger mediante el artículo constitucional, son otros, por ejemplo, los derechos de la niñez, el derecho a alimentos, derecho a salud, derecho a educación, derecho al nombre y su registro, etc., no el derecho a la identidad. 


\section{LA IDENTIDAD PERSONAL, UN DERECHO FUNDAMENTAL EN MÉXICO}

El 17 de junio de 2014, se elevó al rango constitucional el derecho fundamental a la identidad personal, adicionando, para ello, el artículo 4 de la Constitución Política de los Estados Unidos Mexicanos, el párrafo octavo que dice: "Toda persona tiene derecho a la identidad y a ser registrado de manera inmediata a su nacimiento. El Estado garantizará el cumplimiento de estos derechos. La autoridad competente expedirá gratuitamente la primera copia certificada del acta de registro de nacimiento". ${ }^{26}$

El derecho fundamental a la identidad de México se define por los elementos estáticos de la identidad, como son nombre y su registro, filiación, nacionalidad y derecho a conocer los orígenes biológicos, según se desprende de las leyes reglamentarias.

El derecho a conocer los orígenes fue empleado por Argentina para conocer la identidad de los recién nacidos arrebatos por el Estados en la dictadura de 1976 y la legislación mexicana copió esta tendencia, sin embargo, en Argentina el derecho a la identidad no es un derecho fundamental, en cambio, en México si lo es.

\section{REgULACIÓN DEL DERECHO A LA IDENTIDAD}

El derecho a la identidad es un derecho fundamental en México, se establece en el artículo 4 octavo párrafo de la Constitución Política de los Estados Unidos Mexicanos, que establece el derecho de registro inmediato y gratuito de nacimiento.

\footnotetext{
${ }^{26}$ Constitución Política de los Estados Unidos Mexicanos
} 
Asimismo, el artículo 20 constitucional, C. V., establece el derecho de las víctimas para resguardar su identidad y otros datos personales. ${ }^{27} \mathrm{El}$ derecho a la identidad es polisémico, tiene varias connotaciones se utiliza para hablar de identidad personal, identidad nacional, identidad indígena y, según el artículo 20 constitucional, derecho a la privacidad o dato personal.

En cuanto a la identidad personal, la definición del artículo 4, octavo párrafo, de la Constitución, se amplía por la Ley General de los Derechos de Niñas, Niños y Adolescentes. El artículo 19 señala:

Niñas, niños y adolescentes, en términos de la legislación civil aplicable, desde su nacimiento, tienen derecho a:

1. Contar con nombre y los apellidos que les correspondan, así como a ser inscritos en el Registro Civil respectivo de forma inmediata y gratuita, y a que se les expida en forma ágil y sin costo la primer copia certificada del acta correspondiente, en los términos de las disposiciones aplicables;

2. Contar con nacionalidad, de conformidad con lo dispuesto en la Constitución Política de los Estados Unidos Mexicanos y los tratados internacionales;

3. Conocer su filiación y su origen, en la medida de lo posible y siempre que ello sea acorde con el interés superior de la niñez, y

4. Preservar su identidad, incluidos el nombre, la nacionalidad y su pertenencia cultural, así como sus relaciones familiares.

5. (...)

${ }^{27}$ CPEUM. Artículo 20.- El proceso penal será acusatorio y oral. Se regirá por los principios de publicidad, contradicción, concentración, continuidad e inmediación. C. De los derechos de la víctima o del ofendido: $\mathrm{V}$. Al resguardo de su identidad y otros datos personales en los siguientes casos: cuando sean menores de edad; cuando se trate de delitos de violación, trata de personas, secuestro o delincuencia organizada; y cuando a juicio del juzgador sea necesario para su protección, salvaguardando en todo caso los derechos de la defensa. 
De estos textos se desprende que la regulación mexicana define el derecho a la identidad exclusivamente atendiendo a los elementos estáticos de ese derecho. No obstante que, la identidad es un derecho fundamental en México, al prescindir de los elementos dinámicos de la identidad, es decir, aquellos rasgos y características determinados por la conciencia, la regulación se aleja de la protección a los cuestionamientos quién soy - quién eres.

Tanto en la legislación como en la jurisprudencia, el derecho a la identidad tiene como finalidad conocer los orígenes biológicos de las niñas, niños y adolescentes, de aquí que la Ley General de los Derechos de Niñas, Niños y Adolescentes dedica el capítulo tercero al derecho a la identidad.

2. TESIS Y JURISPRUDENCIA MEXICANA Y LA RECREACIÓN DEL DERECHO A LA IDENTIDAD

En cuanto a la actividad judicial entramos tres vertientes en la aplicación del derecho a la identidad: a) Interdependencia de los derechos de los niños, b) Identidad de género, c) Identidad personal y el matrimonio.

\section{a) INTERDEPENDENCIA ENTRE LA IDENTIDAD Y LOS DERE- CHOS DE LAS NIÑAS, NIÑOS Y ADOLESCENTES}

En este rubro relacionamos cinco tesis jurisprudenciales para mostrar lo que hemos venido exponiendo en el desarrollo de este trabajo, - En México se define el derecho a la identidad con base exclusivamente en los elementos estáticos de este derecho; por lo que respecta a menores, los casos se focalizan en el derecho a conocer los orígenes biológicos. - El ejercicio del derecho a la identidad personal, en el sentido de diferencia, se ha destinado 
judicialmente para las niñas, niños y adolescentes. Parece que el derecho fundamental a la identidad en México no protege el derecho de los adultos para preguntarse, como la escritora Sabina Berman, ¿quién soy?, menos protege que la expresión de mi personalidad sea vulnerada con categorías como chairo, fifi, piquis, nini, perrada y demás categorías de picardía mexicana, es decir, ¿đquién eres? - El derecho a conocer la verdad biológica, en estos casos, no protegió el derecho a la identidad; ya que éstos no se motivaron por la incertidumbre de la niña, niño o el adolescente que quería indagar sobre sus orígenes; estos asuntos se iniciaron para imputar o deslindar una paternidad y así proteger los derechos de alimentos del menor o procurar el cuidado de la familia. Por cierto, derechos muy valiosos y fundamentales de acuerdo a nuestra Constitución. Entonces, ¿para qué llamarle derecho a la identidad a otros derechos fundamentales? ¿Será que la identidad mexicana cuyo rasgo distintivo es el deleite por la imprecisión y el doble sentido, trascendió a la ley y de ahí a la actividad judicial? Veremos:

- i) En agosto de 2018, el máximo tribunal emitió el fallo por el cual se pronunció que la ausencia del vínculo biológico en la relación paterno - filial no es suficiente para sustentar la impugnación paternidad, de acuerdo con el interés superior del menor y el derecho a la identidad.

$\mathrm{Al}$ establecer el contenido y alcances del artículo 4o. de la Constitución Federal, esta Suprema Corte de Justicia de la Nación ha sostenido que aunque existe una tendencia a que la filiación jurídica coincida con la filiación biológica, la coincidencia no siempre es posible, sea ya por supuestos tales como la filiación adoptiva o procreaciones asistidas por donación de gametos, por ejemplo, o porque el ordenamiento hace prevalecer en el caso concreto otros valores o intereses que considera más relevantes. (...) una visión tutelar del derecho a la identidad que persigue proteger la conformación de la auto-percepción -como faceta identita- 
ria- y no sólo de necesidades de carácter prestacional. De ahí que el artículo 4o. de la Constitución Federal no implique una facultad irrestricta a los sujetos involucrados en las relaciones familiares para que éstas sean modificadas en todo momento al amparo de la verdad biológica. ${ }^{28}$

Este caso nos muestra como el derecho a conocer la verdad biológica, puede oponerse al derecho a la identidad, por ello es necesario establecer y aplicar el derecho a no saber para una protección de la identidad y derechos interdependientes.

- ii) Fallo de Junio de 2018. En cuanto al derecho a la identidad del menor concebido por medios de reproducción asistida, los fallos de la Corte son incipientes, considera que: “(... ) cuando se empleó un tratamiento por inseminación artificial heteróloga, se dota de contenido bajo una doble connotación: en primer lugar, respecto de las consecuencias jurídicas que surgen por quienes se someten a esos tratamientos; y en segundo lugar, en relación con el impacto que se produce en los hijos nacidos bajo esas técnicas”. ${ }^{29}$

El máximo tribunal omitió argumentar en qué consiste el impacto que se produce en los hijos nacidos con técnicas de reproducción asistida. Además, se plantea un nuevo y de pocos alcances, elemento estático del derecho a la identidad, la forma de concepción de la persona.

- iii) En junio de 2018, se emite la tesis aislada que establece, la identidad de un menor, no sólo constituye la posibilidad de recibir información sobre su nombre, nacionalidad y filiación, a partir del reconocimiento de estos derechos se derivan otros.

${ }^{28}$ Tesis: 1a. XCVI/2018 (10a.), Gaceta del Semanario Judicial de la Federación, Décima Época, t. I, agosto de 2018, p. 1027

${ }^{29}$ Gaceta del Semanario Judicial de la Federación, Décima Época, t. II, junio 2018, p. 955 
El derecho humano a la identidad está protegido por la Constitución Política de los Estados Unidos Mexicanos y por otros instrumentos internacionales, que constituye un derecho por ser un elemento que le es inherente al ser humano y que puede comprender otros derechos, como el derecho al nombre, a la nacionalidad y a conocer su filiación y origen; sin embargo, el núcleo esencial no sólo lo constituye la posibilidad de solicitar y recibir esa información, sino en que a partir de esos derechos se pueden derivar otros distintos, como son los de alimentación, educación, salud y sano esparcimiento.(...) ${ }^{30}$

En esta tesis, se confunde el derecho a la identidad con los derechos ARCO, acceso, rectificación, cancelación y oposición, establecidos en el segundo párrafo del artículo 16 de la constitución.

- iv) En marzo de 2018 se emitió un fallo con carácter de tesis aislada que considera inconstitucional la presunción legal de hijos nacidos del matrimonio, la cual condiciona el registro y reconocimiento de los menores cuando su madre los procree con persona distinta de su cónyuge, a que sea sólo éste pueda reconocerlos como sus hijos y sólo podrán reconocerse por persona distinta al cónyuge cuando éste los hubiere desconocido como hijos suyos y exista sentencia ejecutoria que así lo declare. ${ }^{31}$

- v) El 10 de septiembre de 2014, se determinó que en un juicio de investigación de paternidad, no es obstáculo que obre en el acta de nacimiento del menor, el registro de un padre legal, para admitir la prueba pericial en genética molecular en la persona demandada: “(...) lo que se pretende es proteger la estabilidad de las relaciones familiares y la salud

30 Tesis: 1a. LXXV/2018 (10a.), Gaceta del Semanario Judicial de la Federación, Décima Época, t. II, junio de 2018, p. 956

31 Tesis: (IV Región) 1o.3 C (10a.), Gaceta del Semanario Judicial de la Federación, Décima Época, t. IV, marzo 2018, p. 3483 
mental del menor, la mera admisión de la prueba pericial en genética no afectará por sí sola tales intereses, ya que el juez, de estimarlo conveniente, puede ordenar no dar a conocer los resultados de dicha prueba al menor, si determina que ello es mejor para el niño o niña. (...)” ${ }^{32}$

De las cinco tesis jurisprudenciales, cuatro se refieren a imputación o deslinde de paternidad y una a la identidad del menor concebido por técnicas de reproducción asistida. En conclusión, considera que solo la primera, la emitida el mes de agosto de 2018, es la más próxima a proteger el derecho a la identidad, señala: "una visión tutelar del derecho a la identidad que persigue proteger la conformación de la auto-percepción -como faceta identitaria- y no sólo de necesidades de carácter prestacional”. Este texto soporta la crítica que formulo respecto a la aplicación del derecho a la identidad en México: la reforma al texto constitucional, de 17 de junio de 2014, se ha utilizado para proteger derechos fundamentales de carácter prestacional, diferentes al derecho a la identidad.

\section{b) IDENTIDAD DE GÉNERO}

La identidad es una palabra polisémica y el derecho a la identidad también; así, la palabra y el derecho, respectivamente, significa y protege diferencias e igualdad.

En cuanto al carácter de igualdad del derecho a la identidad, la jurisprudencia ha construido el derecho al cambio del nombre por identidad de genero. Si bien, este derecho ha sido reconocido por la legislación de varias Entidades Federativas, la jurisprudencia ha sentado precedentes para aquéllas que todavía no lo regulan. Así encontramos la siguiente jurisprudencia:

\footnotetext{
32 Tesis: 1a./J. 55/2014 (10a.), Gaceta del Semanario Fudicial de la Federación, Décima Época, t. I, Septiembre de 2014 p. 556
} 
- i) El 7 de junio de 2019, se publicó la Jurisprudencia, por contradicción de tesis, que declara que los artículos 48, 130 Y 131 TER del Código Civil del Estado de Chihuahua, transgreden los derechos a la igualdad, a la identidad y al nombre de las personas transgénero, al contener una discriminación normativa.

En ese sentido, si la modificación del nombre propio y del género no incide en el concepto de identidad, porque no cambian los apellidos ni se pierde la línea de filiación consanguínea con los ascendientes y descendientes, aunado a que no se traduce en una afectación a los datos esenciales del acta, en relación con la voluntad, el objeto y las solemnidades, el procedimiento administrativo sin homologación judicial se estima congruente para el trámite del cambio de nombre propio y de género, la expedición de un nuevo documento y la extensión del reconocimiento de la identidad a las autoridades que guarden relación con esos derechos. Lo anterior es así, toda vez que los diversos procedimientos judicial y administrativo que ameritan la intervención del Juez, sujetan al gobernado a cargas innecesarias relacionadas con la prueba, aunado a que con el procedimiento administrativo sin homologación judicial se satisface el fin legítimo de garantizar el cambio de nombre y sexo de las personas, además porque para la adecuación del acta de nacimiento solamente se requiere el consentimiento libre e informado del solicitante, es decir, se trata de un acto declarativo y no constitutivo de derechos. ${ }^{33}$

Esta jurisprudencia contradice la Ley General de los Derechos de Niñas, Niños y Adolescentes, cuyo capítulo tercero De la identidad, Artículo 19, se desprende que la identidad se conforma por el nombre y su registro, así como la filiación y otros elementos estáticos de la identidad; entonces ¿cómo puede ser que el nombre y el género no incidan en la

${ }^{33}$ Tesis: PC.XVII. J/20 A (10a.), Semanario Judicial de la Federación, Décima Época, t. ,7 de junio de 2019, t. III, pp. 2375, 2376 y 2377 
identidad de las personas? Bueno, si el máximo tribunal no promueve mi derecho a definirme a mi misma como mujer, más aún, limita mi identidad a mi filiación, tengo que concluir que esta jurisprudencia deforma dos derechos: el derecho a la identidad y el derecho fundamental al nombre, cuyos elementos son dos: nombre de pila y patronímicos.

- ii) En octubre de 2017, la Suprema Corte de Justicia de la Nación emitió un fallo por el que determinó que procede la modificación del acta de nacimiento, conforme a una interpretación pro persona, cuando se trate de asentar su contenido conforme a la realidad social, en el entendido de que la enmienda por las que se adecuan los datos de identificación a la realidad social no deberá ser motivo para crear, modificar o extinguir derechos u obligaciones, ni causar perjuicios a terceros, ni que se haga en fraude a la ley. ${ }^{34}$

Si bien, esta tesis jurisprudencial no se pronuncia respecto al cambio de nombre por identidad de género, consideramos que el caso le es aplicable. Este fallo prevé supuestos que omitió analizar la jurisprudencia citada con antelación; atinadamente se reconoce el derecho al cambio de nombre, siempre y cuando la adquisición del nuevo nombre no tenga como finalidad crear, modificar o extinguir derechos y obligaciones que cause perjuicios a terceros. Estas son las situaciones que se deben verificar, por la vía administrativa o judicial, cuando hay una solicitud de cambio de nombre, ello aunque no se cambie la filiación como dice el Tribunal, de cualquier manera hay una afectación a dos derechos fundamentales la identidad y el nombre.

\footnotetext{
${ }^{34}$ Tesis: XII.C.16 C (10a.), Gaceta del Semanario Judicial de la Federación, t. IV, octubre 2017, p. 2398
} 


\section{c) LA IDENTIDAD PERSONAL Y EL MATRIMONIO}

Esta vertiente del derecho a la identidad se propone con motivo de la localización de la siguiente tesis: En marzo de 2016, un fallo de los Tribunales Federales consideró que el matrimonio de mexicanos en el extranjero surte efectos familiares desde que se celebra, aún cuando no se registre en la oficina del registro civil, a fin de no vulnerar la identidad de los contrayentes,

(...), vulneraría el derecho humano a la identidad, porque la falta de inscripción de un matrimonio de mexicanos en el extranjero, no puede tener como consecuencia que deje de reconocerse el estado civil de casado, no sólo en México, sino en cualquier parte del mundo, pues se trata de un atributo de la personalidad que no puede variar de un país a otro. Como todo matrimonio, los celebrados en el extranjero surten efectos familiares y patrimoniales. La nota distintiva de los primeros, es que siempre se producen; dichos efectos se refieren, entre otros, a la filiación que surge con el matrimonio entre los consortes, así como los derechos y obligaciones inherentes a éste, como el afecto, la fidelidad y el apoyo recíproco. ${ }^{35}$

La seguridad jurídica que proporcionan los documentos públicos no se relaciona con el derecho a la identidad. En cuanto a la fidelidad y el apoyo recíproco, estos no son elementos estáticos ni dinámicos de la identidad, en todo caso, el fallo debió fundamentarse en el artículo 4 primer párrafo relativo a la desarrollo de la familia.

\footnotetext{
35 Tesis: III.2o.C.38 C (10a.), Gaceta del Semanario Judicial de la Federación, Décima Época, Tomo II, marzo de 2016, p. 1737
} 


\section{IDENTIDAD GRUPAL}

El derecho a la identidad es un derecho polisémico por ello versa sobre la identidad personal para destacar diferencias individuales y también, respecto a la identidad grupal para proteger los rasgos comunes entre las personas que forman grupos, esos rasgos comunes generan pertenencia al grupo e inciden en la identidad personal.

En México tienen carácter de derechos fundamentales reconocidos en la Constitución Política de los Estados Unidos Mexicanos, la identidad indígena ${ }^{36}$ y la identidad nacional. ${ }^{37}$

Aunque no tengan carácter de derecho fundamental cada grupo forma su propia identidad por ejemplo, la familia, la universidad, amigos, iglesia, partidos políticos, etc.

Con relación a la identidad nacional, se emitió el fallo por el cual se ordenó el cese de un profesor que se abstiene de rendir honores a la bandera nacional y entonar el himno nacional:

(...), el profesor de educación primaria tiene la obligación de fomentar en el educando el amor a la patria y la conciencia de la nacionalidad, la independencia y la justicia; de tales disposiciones también se infiere que el Escudo, la Bandera y el Himno Nacionales son símbolos patrios de la República, en cuan-

${ }^{36}$ CPEUM Artículo 20. La Nación Mexicana es única e indivisible. La Nación tiene una composición pluricultural sustentada originalmente en sus pueblos indígenas que son aquellos que descienden de poblaciones que habitaban en el territorio actual del país al iniciarse la colonización y que conservan sus propias instituciones sociales, económicas, culturales y políticas, o parte de ellas.

La conciencia de su identidad indígena deberá ser criterio fundamental para determinar a quiénes se aplican las disposiciones sobre pueblos indígenas. (...)

${ }^{37}$ Artículo 6o. B. En materia de radiodifusión y telecomunicaciones: III. La radiodifusión es un servicio público de interés general, por lo que el Estado garantizará que sea prestado en condiciones de competencia y calidad y brinde los beneficios de la cultura a toda la población, preservando la pluralidad y la veracidad de la información, así como el fomento de los valores de la identidad nacional, contribuyendo a los fines establecidos en el artículo 3o. de esta Constitución. 
to constituyen los elementos fundamentales de identidad de los mexicanos, reconociéndose en ellos un patrimonio cultural común; por tanto, es evidente que el maestro, por su profesión y la calidad de trabajo que desempeña, está obligado a fomentar en sus alumnos la costumbre cívica de rendir honores a la Bandera Nacional y a entonar respetuosamente el Himno Nacional, con la finalidad de fortalecer las raíces históricas y los lazos culturales y sociales que nos unen y nos identifican como Nación. (...) ${ }^{38}$

Los rasgos comunes para los mexicano de acuerdo a este fallo son el escudo, la bandera y el himno nacional, a lo cual agregaría muy breve, también el lenguaje e historias, forman parte de la identidad nacional.

\section{CONCLUSIONES}

1. La palabra identidad es polisémica y sus significados, no sólo son diversos sino además, pueden ser antónimos; así encontramos, se emplea la palabra identidad tanto para hablar de rasgos comunes o iguales, como para hablar de rasgos diferentes.

2. El derecho a la identidad es polisémico, encontramos en la constitución y jurisprudencia derechos a la identidad que protegen diferentes aspectos de la personalidad: la identidad personal, la identidad indígena, identidad nacional y el derecho al cambio de nombre por identidad de género.

3. En México, hay un gusto por la palabra imprecisa, el juego de palabras y las frases con doble o múltiple sentido y parece que ese rasgo popular se traslado al ámbito jurídico por lo que respecta al derecho a la identidad.

4. La regulación y aplicación imprecisa del derecho a la identi-

\footnotetext{
38 Tesis: 4a./J. 41/94, Gaceta del Semanario Judicial de la Federación, Octava Época, octubre 1994, p. 20
} 
dad le ha quitado cobijo a otros derechos fundamentales como el nombre, la nacionalidad, los alimentos, e incluso, la misma identidad personal ha quedado desprotegida en parte.

5. La presencia de la conciencia en el derecho a la identidad, significa que la persona tiene el derecho a preguntarse y a investigar, quién soy yo - quiénes somos- quién eres.

6. El derecho a la identidad comprende dos tiempos, el primero es interno, en el cual uno a sí mismo se plantea ¿Quién soy yo?, o, ¿Quiénes somos nosotros? y el segundo o externo cuando con base en percepciones se define ¿Quién eres?, ¿Quiénes son ustedes? La exteriorización viene a confirmar la verdadera personalidad.

7. Por caminos diferentes se erigió el derecho a la identidad; mientras que en Italia la doctrina y los Tribunales definían el derecho a la identidad, analizando casos de robo de identidad, colisión de derechos como el interés de exteriorización de la personalidad contra la libertad de expresión y otros casos recursos del derecho a la identidad; en Argentina durante la última dictadura, 1976, se violaba sistemáticamente el derecho a la identidad de las familias y recién nacidos secuestrados por el Estado.

8. La identidad personal se integra con las característica y rasgos que las personas encontramos en nosotros mismos, algunos de estos rasgos son iguales a los de otros, por ejemplo a los integrantes de la nación, etnia, familia, universidad, religión, partido político, grupo de amigos, etc; y, a su vez, el conjunto de rasgos y características, nos permite asumirnos conscientemente como seres únicos y diferentes a todas las demás personas.

9. El derecho a la identidad tiene dos tipos de elementos, los 
estáticos y los dinámicos.

10. Los elemento estáticos del derecho a la identidad pueden ser el nombre, la genética, la filiación, la nacionalidad, el género, la fecha de nacimiento, el lugar de nacimiento, en general, todos aquellos que permitan definir quién soy yo - quién eres.

11. Los elementos dinámicos de la identidad son aquéllas características y rasgos determinados por la conciencia, los cuales cambian según nuestras vivencias; estos nos ayudan a delimitar internamente quién soy y externamente reflejan quién eres. Por ejemplo, quehacer, creencias, grupos de pertenencia, virtudes $\mathrm{y}$ vicios, lugares favoritos, historias y experiencias, certidumbres y temores, amores y odios, etc. Los elementos dinámicos cambian continuamente hasta que la persona muere.

12. La regulación mexicana define el derecho a la identidad exclusivamente atendiendo a los elementos estáticos de ese derecho. No obstante que, la identidad es un derecho fundamental en México, al prescindir de los elementos dinámicos de la identidad, es decir, aquellos rasgos y características determinados por la conciencia, la regulación se aleja de la protección a los cuestionamientos quién soy - quién eres.

13. Tanto en la legislación como en la jurisprudencia mexicana, el derecho a la identidad tiene como finalidad conocer los orígenes biológicos de las niñas, niños y adolescentes, de aquí que la Ley General de los Derechos de Niñas, Niños y Adolescentes dedica el capítulo tercero al derecho a la identidad.

14. El derecho mexicano, debería excursionar sobre el derecho a no saber, a fin de proteger el derecho a la identidad de las personas.

15. En los casos jurisprudenciales revisados, el derecho a conocer 
la verdad biológica, no protegió el derecho a la identidad, ya que éstos no se motivaron por la incertidumbre de la niña, niño o el adolescente que quería indagar sobre sus orígenes; estos asuntos se iniciaron para imputar o deslindar una paternidad y así proteger los derechos de alimentos del menor o procurar el cuidado de la familia.

16. En la legislación mexicana y sobre todo en la actuación judicial, el derecho a la identidad se confunde con otros derechos, por ejemplo con el derecho al nombre, alimentos, filiación, derechos ARCO, derecho de registro de nacimiento, seguridad jurídica en el caso de derecho de reconocimiento de matrimonio contraído en el extranjero.

17. En la doctrina, legislación y actividad judicial mexicana falta claridad del concepto, elementos y finalidades del derecho a la identidad, lo que se muestra con la pobre protección judicial de ese derecho.

\section{FUENTES}

\section{BIBLIOGRAFIA}

Borges, Jorge Luis, "Biografía de Tadeo Isidoro Cruz (1829-1874)”, El Aleph, Buenos Aires, 1949.

Fernández Sessarego, Carlos, "Derecho a la identidad Personal", Comparazione e Diritto Civile, 1992, p. 29, http://www.comparazionedirittocivile.it/ prova/files/sessarego_derecho.pdf

Frazer, James George, La rama dorada: Magia y religión, 3a ed., trad. de Elizabeth Campuzano y Tadeo I. Campuzano, México, Fondo de Cultura Económica, 2011. 
Gómez Bengoechea, Blanca, Derecho a la Identidad y filiación: búsqueda de orígenes en adopción internacional y en otros supuestos de filiación transfronteriza, Madrid, Dykinson, 2007.

Morgan, Lewis Henry, La sociedad primitiva, Madrid, Ayuso, 1970, t. I, p. 141

PuINER, Adolfo, El nombre de las personas, 2a ed., Argentina, ASTREA, 199X.

Shakespeare, William, La tragedia de Hamlet, príncipe de Dinamarca, Londres, 1605.

Uría Acevedo, María de las Mercedes Ales, El derecho a la identidad en la filiación, Valencia, Tirant lo Blanch, 2012.

\section{HEMEROGRAFÍA}

Cantoral Domínguez, Karla, "Construcción jurisprudencial del derecho a la identidad”, Nexo Furídico, Focus Regit Actum, México, año VI, número 23, octubre - diciembre 2014.

Cifuentes Santos, "Protección jurídica de la vida privada y de la identidad personal”, Anales de la Academia Nacional de Derecho y Ciencia Sociales de Buenos Aires, año XLVI, número 39, 2001.

Crovi, Luis Daniel, “El Derecho a la Identidad y sus Alcances”, Derecho de Familia y de las Personas, Argentina, año VI, número 3, abril 2014.

Tourliere, Mathieu, "Pobre naces, pobre te quedas", Revista Proceso, 18 de mayo de 2019, https://www.proceso.com.mx/584668/pobre-naces-pobre-te-quedas

\section{LEYES}

Constitución Política de los Estados Unidos Mexicanos

Ley General de los Derechos de Niñas, Niños y Adolescentes 


\section{JURISPRUDENCIALES}

Tesis: PC.XVII. J/20 A (10a.), Semanario Judicial de la Federación, Décima Época, t. ,7 de junio de 2019, t. III.

Tesis: 1a. XCVI/2018 (10a.), Gaceta del Semanario Judicial de la Federación, Décima Época, t. I, agosto de 2018.

Gaceta del Semanario Judicial de la Federación, Décima Época, t. II, junio 2018.

Tesis: 1a. LXXV/2018 (10a.), Gaceta del Semanario Judicial de la Federación, Décima Época, t. II, junio de 2018.

Tesis: (IV Región)10.3 C (10a.), Gaceta del Semanario Judicial de la Federación, Décima Época, t. IV, marzo 2018.

Tesis: XII.C.16 C (10a.), Gaceta del Semanario Judicial de la Federación, t. IV, octubre 2017.

Tesis: III.2o.C.38 C (10a.), Gaceta del Semanario Judicial de la Federación, Décima Época, Tomo II, marzo de 2016.

Tesis: 1a./J. 55/2014 (10a.), Gaceta del Semanario Judicial de la Federación, Décima Época, t. I, Septiembre de 2014.

Caso Gelman Vs Uruguay, 24 de febrero de 2011, Corte Interamericana de Derechos Humanos

Corte de Casación Italiana, 22 de junio de 1985, caso Veronesi. 